\title{
POLÍTICA NACIONAL DE EXTENSÃO UNIVERSITÁRIA: ANÁLISE DA EXPERIÊNCIA DO INSTITUTO DE CIÊNCIAS DA SAÚDE DA UFPA ${ }^{1}$
}

\author{
Durbens Martins Nascimento \\ Universidade Federal do Pará \\ durbens.naea@gmail.com \\ Cristina Frassinette Lima de Souza Souza \\ Universidade Federal do Pará \\ frantte@ufpa.br
}

\section{Resumo}

Este estudo objetiva tratar sobre a extensão universitária, abordada a partir dos conceitos de universidade, organização, conhecimento e extensão. Busca-se com o presente trabalho verificar se os produtos gerados, por via de projetos, nas práticas extensionistas desenvolvidas pelo ICS/UFPA, cumprem as prerrogativas da Política Nacional de Extensão Universitária. Foram analisadas as práticas extensionistas do Instituto de Ciências da Saúde (ICS) da Universidade Federal do Pará (UFPA) à luz da Política Nacional de Extensão Universitária (PNEU), compreendida dentro da interação dialógica, da interdisciplinaridade e interprofissionalidade, da indissociabilidade ensino-pesquisa-extensão, do impacto na formação do estudante e do impacto e transformação social, contemplada na Política de Extensão da UFPA. A metodologia da pesquisa seguiu uma abordagem quantitativa e qualitativa com aporte bibliográfico e documental. Selecionaram-se para análise deste estudo 80 projetos e 60 relatórios de extensão do ICS do ano de 2012. Os resultados revelaram que as prerrogativas da PNEU ficaram muito aquém de serem atingidas pelos produtos do ICS, quando se tratou de interdisciplinaridade e interprofissionalidade, indissociabilidade ensino-pesquisa-extensão, e, impacto e transformação social. Além disso, foi encontrada pouca participação por parte dos docentes, discentes e técnico-administrativos do ICS em dita atividade. Concluiuse que o modelo de extensão do ICS é assistencial, desenvolvido através de prestação de serviços.

Palavras-chave: Política Nacional de Extensão Universitária. Extensão na UFPA. Bolsas de Extensão. Instituto de Ciências da Saúde.

\section{NATIONAL UNIVERSITY EXTENSION POLICY: ANALYSIS OF THE EXPERIENCE OF THE INSTITUTE OF HEALTH SCIENCES OF UFPA}

\begin{abstract}
The current study purpose refers to the university extension, addressing the concepts of university, organization, knowledge andextension. We sought to answer the following question: Does the outcome that has been generated through projects on extension practices developed by ICS/UFPA actually fulfill the guidelines of the National University Extension Policy? The pursued objective consisted in a general analysisof the extension practices of the Institute of Health Sciences (ICS) at the Federal University of Pará (UFPA) in the light of the National University Extension Policy (NUEP), comprehending dialogical interaction, interdisciplinary and interprofessionalism, teaching-research-extension inseparability, impact on student training, and impact and social transformation envisaged within the Policy Extension of UFPA. The research methodology comprehended a quantitative and qualitative approach supported by bibliographic and documentary supply. It was consulted the collection of various documents, given more evidence to those focused on the university extension in 2012, contained into several instances of UFPA. A number of 80 projects and 60 reports of extension of ICS were selected for analysis in the year 2012. The results revealed that the guidelines of PNEU fell far short of being reached by the ICS products, when it came to interdisciplinarity and interprofessionalism, teaching-research-extension inseparability, and impact and social transformation. Furthermore, there was little participation by teachers, students and administrative technicians of ICS in such activity. It was concluded that the extension model of ICS consists is a welfare model, developed through service provision.

Keywords: National University Extension Policy. UFPA Extension. Scholarships. Institute of Health Sciences.
\end{abstract}

${ }^{1}$ Este artigo é resultado da Dissertação "Política Nacional de Extensão Universitária: Análise da Experiência do ICS da UFPA", defendida e aprovada com o conceito B em 2013, no Programa de Pós-Graduação em Desenvolvimento Sustentável do Trópico Úmido do Núcleo de Altos Estudos Amazônicos da Universidade Federal do Pará (NAEA/UFPA). 


\title{
POLÍTICA NACIONAL DE EXTENSIÓN UNIVERSITARIA: ANÁLISIS DE LA EXPERIENCIA DEL INSTITUTO DE CIENCIAS DE LA SALUD DE LA UFPA
}

\begin{abstract}
Resumen
Este estudio tiene como objetivo analizar cómo la extensión de la universidad, abordada a partir de los conceptos de universidad, organización, conocimiento y extensión, si los productos generados, por medio de proyectos, en las prácticas de extensión desarrolladas por el ICS/UFPA, cumplen las prerrogativas de la Política Nacional de Extensión Universitaria (PNEU). Las prácticas extensivas ICS de la UFPA fueron analizadas a la luz de la PNEU, dentro de la interacción dialógica, interdisciplinaria e interprofesional, inseguridad enseñanza-investigación-extensión, y su impacto en la formación de los alumnos, así como en la inclusión social si contemplados en la Política de Extensión de la UFPA . La metodología de la investigación siguió un abordaje cuantitativo y cualitativo con investigación bibliográfica y documental. Se seleccionaron 80 proyectos y 60 informes de extensión del ICS para el año 2012. Los resultados revelaron que las prerrogativas de la PNEU estaban lejos de ser alcanzadas por los productos ICS cuando se trata de interdisciplinaridad e interprofesionalidad, inseguridad enseñanza-investigación-extensión, e impacto social y transformación.

Palabras clave: Extensión. Ciencias de la Salud. Plan Nacional de Extensión.
\end{abstract}




\section{INTRODUÇÃO}

O ano de 2010 marca o surgimento do fortalecimento do conceito de extensão universitária proposto pelo Fórum de Pró-Reitores de Extensão Universitária (FORPROEX), que regulamenta a parceria entre universidades e sociedade e atribui maior responsabilidade às Instituições de Ensino Superiores (IES). A partir daí, a intenção da política é a de se fazer a interface entre o tripé pesquisa/ensino/extensão do governo federal na Política Nacional de Extensão Universitária (PNEU) em consonância com as prerrogativas do FORPROEX.

Na Universidade Federal do Pará (UFPA), instituição acadêmica Multicampi, reconhecida por ser uma instituição de ensino superior pioneira na Região Amazônica e que há mais de 50 anos vem atuando na formação de recursos humanos. O portal de avaliação de revistas SCI mago Journal and Country Rank, que inclui o indicador de prestígio científico de revistas SJR, demonstrou que a UFPA foi a instituição da Amazônia que mais produziu e publicou documentos científicos em 2012.

Contudo, é preciso avaliar se essa publicação contempla a extensão universitária. Desse modo, fica perceptível no PDI 2011-2015 da UFPA o enquadramento dos cinco eixos estabelecidos na PNEU (2012, p. 16) referenciados na interação dialógica, interdisciplinaridade e interprofissionalidade, indissociabilidade ensino-pesquisa-extensão, impacto na formação do estudante e impacto e transformação social.

Com o tema Extensão na UFPA por meio do Instituto de Ciências da Saúde (ICS) da UFPA, este estudo objetiva analisar o papel desta Unidade da UFPA na extensão à luz da Política Nacional de Extensão Universitária. A escolha desta se justifica por ter sido a Unidade Acadêmica, selecionada dentre as demais, que apresentou, anualmente, maior quantitativo de projetos de extensão da UFPA. O recorte temporal abrange o período de 1999-2012. A investigação busca verificar em que medida os produtos gerados, por via de projetos, nas práticas extensionistas desenvolvidas pelo ICS/UFPA, cumprem as prerrogativas da Política Nacional de Extensão Universitária.

\section{UNIVERSIDADE FEDERAL DO PARÁ (UFPA)}

A Universidade Federal do Pará (UFPA), sediada na cidade de Belém, Estado do Pará, localizada na região amazônica, foi criada pela Lei no 3.191, de 02 de julho de 1957 e, atualmente estruturada pelo Decreto no 81.520 de 04 de abril de 1978. A UFPA “[...] caracteriza-se como 
universidade multicampi”, “[...] com autonomia didático-científica, disciplinar, administrativa e de gestão financeira e patrimonial" (UNIVERSIDADE FEDERAL DO PARÁ, 2009, p. 18). Em Belém, estão instaladas 12 Unidades Acadêmicas (Institutos) responsáveis pela formação profissional em graduação e pós-graduação, em área específica do conhecimento, de caráter interdisciplinar; 3 Unidades Acadêmicas Especiais: Escola de Aplicação e 2 Hospitais Universitários integrados as atividades de ensino, pesquisa, extensão, estágio e experimental na residência médica; e 4 Núcleos, com autonomia acadêmica e administrativa, desenvolvem programas de pós-graduação de natureza transdisciplinar. (UNIVERSIDADE FEDERAL DO PARÁ, 2012).

O Projeto Político Pedagógico (PPP) na UFPA, de acordo com Art. 62 da Resolução nº. 3.633/2008-CONSEPE (UNIVERSIDADE FEDERAL DO PARÁ, 2008) foi elaborado com a participação da comunidade acadêmica dos respectivos cursos, composto por um conjunto de experiências, estágios e situações de ensino-aprendizagem direcionadas à formação do discente por meio de conteúdos comuns, específicos e atividades complementares, cadastrados no Sistema de Registro Acadêmico sob o título de Atividades Curriculares.

A política de pesquisa na UFPA, normatizada pela Resolução no 3.043/2003, compreendeu grupos de pesquisa nas áreas das Ciências Agrárias, Biológicas, Saúde, Exatas e da Terra, Humanas, Sociais Aplicadas, Engenharias, Linguísticas, Letras e Artes. (UNIVERSIDADE FEDERAL DO PARÁ, 2009). A pesquisa, na UFPA, objetiva a capacitação do corpo docente e técnicoadministrativo intra e extrainstitucional na pós-graduação latu sensu e stricto sensu. Para os alunos de graduação, disponibiliza o Programa Institucional de Bolsas de Iniciação Científica (PIBIC). (UNIVERSIDADE FEDERAL DO PARÁ, 2009).

A extensão na UFPA segue o conceito proposto pelo FORPROEX (2001) que o entende como um "processo educativo, cultural e científico, articulado ao ensino e à pesquisa de forma indissociável, que visa estabelecer uma relação transformadora entre a Universidade e a sociedade por meio de ações interdisciplinares da comunidade acadêmica" (UNIVERSIDADE FEDERAL DO PARÁ, 2009, p. 37), visando assim à formação de cidadãos críticos para a produção e socialização do conhecimento. As atividades de Extensão na UFPA foram regulamentadas a partir de 7/3/2005, pela Resolução n. ${ }^{\circ} 3.298 /$ CONSEPE/UFPA, que a concebe em seu Art. $1^{\circ}$ o conceito:

[...] conjunto de atividades acadêmicas, de caráter múltiplo e flexível, que se constitui num processo educativo, cultural e científico, articulado ao ensino e à pesquisa, de forma indissociável, e que viabiliza, através de ações concretas e contínuas, a relação transformadora entre a Universidade e a sociedade. (UNIVERSIDADE FEDERAL DO PARÁ, 2005, não paginado). 
Na UFPA, a extensão se realiza "por meio de ações interdisciplinares da comunidade acadêmica objetivando a formação cidadã, a produção, e a socialização do conhecimento" (UNIVERSIDADE FEDERAL DO PARÁ, 2009, p. 37). Nessa perspectiva, a interdisciplinaridade é a ação que influencia a formação acadêmica pactuada na dialética de teoria/prática/reflexão/prática, visando à formação transformadora. A extensão da UFPA se desenvolve por vias de instância deliberativa: a PROEX e Coordenações Acadêmicas de Extensão. Vinculada à Reitoria da UFPA, a PROEX propõe metas para a extensão, consonante às diretrizes estabelecidas no Plano Nacional de Extensão, na Política Nacional de Extensão Universitária e nos Fóruns de extensão. Além disso, a PROEX coordena, acompanha e avalia as atividades extensionistas. Essas ações são regulamentadas pelo Regimento Geral da Universidade, que incube a PROEX de propor aos Conselhos Superiores normas e políticas afins, bem como fomentar, acompanhar, avaliar, articular e divulgar as iniciativas e eventos no âmbito interno e externo da Universidade (UNIVERSIDADE FEDERAL DO PARÁ, 2012, p. 81). As modalidades extensionistas se dão na UFPA, em consonância com o FORPROEX (2001), constituindo-se como elementos identitários, contribuindo na elaboração de bases comuns para orientar a instituição e gestão dos projetos, na medida em que traz diretrizes para pensar o cotidiano de atuação.

\section{POLÍTICA NACIONAL DE EXTENSÃO UNIVERSITÁRIA (PNEU)}

Manifestada na Carta de Manaus pelo FORPROEX, a PNEU partiu do pressuposto que não se constrói uma universidade com imposição de modelos excludentes e unívocos (PNEU, 2012). A universidade é um espaço cuja riqueza se sustenta justamente na diversidade, na universalidade, na coexistência de múltiplas concepções, teorias, metodologias e processos (PNEU, 2012).

A PNEU estabelece a modalidade de cursos, eventos, prestação de serviços, programas e projetos nas áreas temáticas de comunicação, cultura, direitos humanos e justiça, educação, meio ambiente, saúde e tecnologia e trabalho, compreendendo os eixos em interação dialógica, interdisciplinaridade e interprofissionalidade, indissociabilidade ensino-pesquisa-extensão, impacto na formação do estudante e, impacto e transformação social, cuja diretriz deve orientar a formulação e implementação das ações de extensão universitária, pactuados pelo FORPROEX, de maneira mais 
ampla e aberta (NOGUEIRA, 2000). Trataremos sobre estes eixos a seguir para nortear esta pesquisa e discutir sobre o caso do Instituto de Ciências da Saúde:

a) Interação dialógica, concebida como uma ação de mão-dupla. Estabelece uma valorização de alianças entre universidade e organizações sociais, com pessoas inseridas nas comunidades, estatais e não estatais, a partir da troca de saberes.

b) Interdisciplinaridade e interprofissionalidade se combinam através de especialização e visão holística. Tais aspectos concretizam-se pela interação de modelos, conceitos e metodologias advindas de diferenciadas disciplinas e áreas do conhecimento, assim como da construção de parcerias intersetoriais, interorganizacionais e interprofissionais.

c) Indissociabilidade do ensino-pesquisa-extensão se efetiva vinculada ao processo de formação de pessoas (ensino); da produção de conhecimento (pesquisa) através de metodologias participativas com atores sociais em um diálogo no formato de investigação-ação ou pesquisa-ação, envolvendo pós-graduandos na extensão, priorizando métodos de análise inovadores de avaliação dos resultados (ou produtos) da ação e seus impactos sociais. A indissociabilidade, incorporada aos programas de pós-graduação, conduz à qualificação das ações de extensão e da própria pósgraduação.

d) impacto na formação do estudante possibilita aportes necessários à formação do mesmo, tanto pela ampliação do universo de referência quanto pelo contato direto com as grandes questões contemporâneas, o que contribui para o fortalecimento do saber discente em termos teóricos e metodológicos, de modo que se criam espaços para reafirmação e materialização dos compromissos éticos e solidários das IES.

e) Impacto e transformação social estabelece uma inter-relação da universidade com os setores sociais numa atuação transformadora, voltada aos interesses e necessidades da maioria da população, para o desenvolvimento social e regional e aprimoramento das políticas públicas, contribuindo para o processo de (re) construção da Nação e da própria universidade que também pode sofrer impacto, ser transformada. 


\section{METODOLOGIA}

Definiu-se como método de procedimento a pesquisa descritiva sob a forma de um estudo de maior amostragem de uma Unidade Acadêmica da UFPA, o ICS. Buscou-se no portal de Periódicos da Coordenação de Aperfeiçoamento de Pessoal de Nível Superior (CAPES), estudos que discutam a extensão praticada nas Instituições de Ensino Superiores brasileiras, abrangendo as diretrizes contempladas nos 5 eixos da PNEU.

Realizou-se um estudo descritivo e analítico, na perspectiva de identificar o papel que a extensão do ICS/UFPA representa na disseminação e aplicação do conhecimento, levando em consideração as diretrizes contempladas nos 5 eixos da PNEU, institucionalizada na UFPA.

Desse modo, a investigação, foi pautada na abordagem quantitativa e qualitativa, que para Bogdan e Biklen (1994) podem ser complementares e que em alguns estudos isto é desejável, por exemplo, aplicando estatísticas descritivas concomitantes a interpretação de dados qualitativos. Tais abordagens justificam-se pela necessidade do próprio objeto; em virtude de seus objetivos, quais sejam: conhecer, levantar, registrar, identificar e analisar para compreender a realidade da atuação do ICS nas práticas de extensão.

Assim, a metodologia adotada seguiu-se por visitas a setores da UFPA que comportam a questão da extensão e ao próprio ICS como se verifica:

\section{a) Pró-Reitoria de Extensão}

Para a abordagem quantitativa, realizou-se o levantamento nos arquivos da PROEX/UFPA das propostas e relatórios de programas, projetos, cursos, prestação de serviços e eventos, desenvolvidos nas Unidades Acadêmicas. Identificou-se que somente se encontravam disponíveis na memória da PROEX as propostas e relatórios de programas e projetos, dos anos de 1999 a 2012. Em seguida, procedeu-se organização anual identificando que o projeto era a ação de maior proposição extensionista pelas mesmas. Elaborou-se um banco de dados no programa Excel, registrando no referido recorte temporal, o quantitativo de projetos por Unidade Acadêmica e em seguida a representação em um gráfico de linha.

\section{b) Instituto de Ciências da Saúde - ICS}

Para abordagem qualitativa deste estudo, localizou-se uma vasta gama de documentos nas PróReitorias da UFPA que subsidiaram dados qualitativos para este estudo. A fonte de pesquisa documental se realizou na PROEX. Selecionamos 80 projetos e 60 relatórios de extensão do ICS da 
UFPA preenchidos em formulário normatizado pela PROEX. Tais documentos estavam arquivados nas pastas A-Z e por unidade acadêmica. O sistema de registro das atividades de extensão encontrava-se computados no formato de planilhas, compartilhadas nos computadores da diretoria da divisão de extensão da PROEX.

\section{c) Pró-Reitoria de Extensão}

Após a identificação que nos projetos do ICS tinham uma média de $60 \%$ de idênticas ações propostas, nos anos de 1999 a 2012, pelos mesmos coordenadores com mesma perspectiva de estudo, decidiu-se destacar projetos e relatórios do ano de 2012, ano este de maior proximidade da realização deste estudo, correspondendo o montante de 80 projetos cadastrados na PROEX e 60 relatórios enviados pelos coordenadores à mesma.

A proposta elaborada pelo(s) extensionista(s), seguindo formulário da PROEX, se deu em nível micro nas subunidades acadêmicas. Iniciativas foram tomadas de forma individualizada e outras conjuntamente com os colaboradores (docentes e técnicos).

A aprovação dos projetos de extensão na UFPA ocorreu nos colegiados das subunidades acadêmicas, que os encaminharam para análise e parecer junto ao Comitê de Extensão e esse para homologação, em nível macro, junto a Congregação do ICS, enviando-as à PROEX para cadastro e submissão, via edital, para alcance de recursos financeiros e/ou de bolsas para graduandos.

Buscou-se, através de Relatório Anual de Atividades de 2012, dados quantitativos e qualitativos que contribuíram para composição e reflexão dos capítulos que referenciam essas e demais Pró-Reitorias e Unidades Acadêmicas da UFPA, em especial, o ICS.

\section{d) Do tratamento e análise dos dados}

Para o tratamento das informações coletadas, contou-se com o aporte da pesquisa bibliográfica e documental. Na primeira, definindo alguns conceitos analíticos, tais como: universidade; organização; conhecimento; extensão. Priorizaram-se autores como: Humboldt, Pereira, Brunner, Almeida, Severino; Chauí, Tolbert e Zucker, Estrada; Teixeira, Descarte, Cervo, Bervian e Da Silva, Antunes, Kant, Oliveira; Gurgel,Fontes.

O levantamento documental fez parte do processo investigativo, a partir de fontes como: leis, estatutos, resoluções, regimentos, Plano Diretor Institucional (PDI), plano e política de extensão, projetos, relatórios, pois, possibilitaram ampliar o entendimento de objetos que necessitaram serem refletidos na contextualização histórica e sociocultural. Além disso, os 
Política Nacional de Extensão Universitária: análise da experiência do Instituto de Ciências da Saúde da UFPA

documentos, mais especificamente projetos, relatórios, planos, e resoluções, trouxeram sistematizado um conjunto de informações que se fizeram de fundamental importância à análise da extensão do ICS.

Os dados foram tratados com suporte estatístico e teorias explicativas, que possibilitaram identificar a relação entre o que se tem discutido sobre o assunto e o estado da arte da extensão universitária na UFPA, tomando como unidade de análise o ICS.

A construção do banco de dados, no programa Excel, metodologia que assumiu a abordagem quantitativa, sintetizou-se os projetos e relatórios por subunidade acadêmica do ICS. Assim, o mapeamento, por via de projetos e relatórios, seguiu os indicadores: projeto, lócus da ação, componentes, proposição de carga horária, titulação, carga horária de contrato de trabalho na UFPA, objetivo(s), produto(s) gerado(s), identificação dos eixos da PNEU (indicadores capazes de expressar a relação institucional da extensão e âmbitos como prática acadêmica, universidade com a sociedade), número de usuários e bolsas.

$\mathrm{Na}$ elaboração da matriz para a análise, decidiu-se, inicialmente, classificar o título dos projetos por sequência numérica seguida por letras minúsculas, das iniciais dos cursos, destinaram-se aos componentes dos projetos como forma de resguardar tais extensionistas.

\section{INSTITUTO DE CIÊNCIAS DA SAÚDE (ICS/UFPA)}

A administração central do ICS está instalada na Praça Camilo Salgado $\mathrm{n}^{\circ}$ 1, bairro do Umarizal, na cidade de Belém-PA. O Instituto foi criado através da Resolução no 626 CONSUN/UFPA, de 24 de setembro de 2007. O Art. 41, da referida Resolução, foi alterado pela Resolução n 688 (CONSUN/UFPA) de 16 de dezembro de 2010, para inclusão na estrutura organizacional do ICS da Faculdade de Fisioterapia e Terapia Ocupacional. Para o desenvolvimento das atividades acadêmicas, o ICS busca a "interlocução interdisciplinar e multiprofissional" (ART. $3^{\circ}$, PARÁGRAFO ÚNICO, REGIMENTO DO INSTITUTO DE CIÊNCIAS DA SAÚDE, 2010).

Os princípios do ICS têm como fundamento:

I - defesa do ensino público, gratuito, de qualidade, laico e socialmente referenciado; II universalização do conhecimento; III - autonomia universitária; IV- gestão democrática; Vrespeito à ética e a diversidade étnica, cultural, sexual e biológica; VI- pluralismo de ideias e pensamentos; VII- indissociabilidade entre ensino, pesquisa e extensão; VIII- busca da excelência acadêmica; IX- defesa dos direitos humanos e a preservação do meio ambiente; 
X-compromisso social e o fortalecimento das parcerias e do dialogo com a sociedade. (UNIVERSIDADE FEDERAL DO PARÁ, 2010, não paginado).

Embora definidos esses princípios, sabe-se que na vida cotidiana da universidade nem sempre são percebidos pela comunidade acadêmica em geral.

O ICS possuiu 361 docentes, destes, 8\% tiveram carga horária de 20h, 44\% com 40h e 48\% são de dedicação exclusiva. Existiram 5,5\% que possuíram somente graduação, 15\% especialização, $44 \%$ mestrado e 36\% doutorado. O curso de medicina representou-se com menor titulação de graduados na categoria docente, $24 \%$, seguido da enfermagem com $2 \%$. Já com titulação de doutorado, o curso que apresentou maior representatividade de titulação docente foi farmácia, com 77\% doutores, seguidos por odontologia com 48\%; nutrição com 35\%; fisioterapia e terapia ocupacional com 33\%; medicina com $29 \%$; e, enfermagem com $23 \%$.

Em 2012, os recursos orçamentários disponibilizados para o ICS, na ordem de R $\$ 281.475,25$, corresponderam a 0,04\% do orçamento da UFPA. Tal recurso foi distribuído entre as subunidades acadêmicas utilizando-se o critério do número de alunos matriculados e concluintes.

No ano de 2012 foram matriculados 2.573 alunos. A maior oferta de vagas se concentrou no curso de medicina, com 150/ano. Os cursos de menor oferta, 34 vagas, foram os de fisioterapia e de terapia ocupacional, implantados, o primeiro no ano de 2010 e o segundo em 2011.

O apoio financeiro ofertado a discentes, mediante bolsa de extensão, foi instituído pela Lei de Diretrizes e Bases da Educação Nacional (LDB) 9.394/96, estabelecendo que as ações de extensão “[...] poderão receber apoio financeiro do Poder Público, inclusive mediante bolsas de estudo". (BRASIL, 1971, não paginado).

Gráfico 1 - Bolsas de extensão ofertadas em 2012 para cursos de graduação

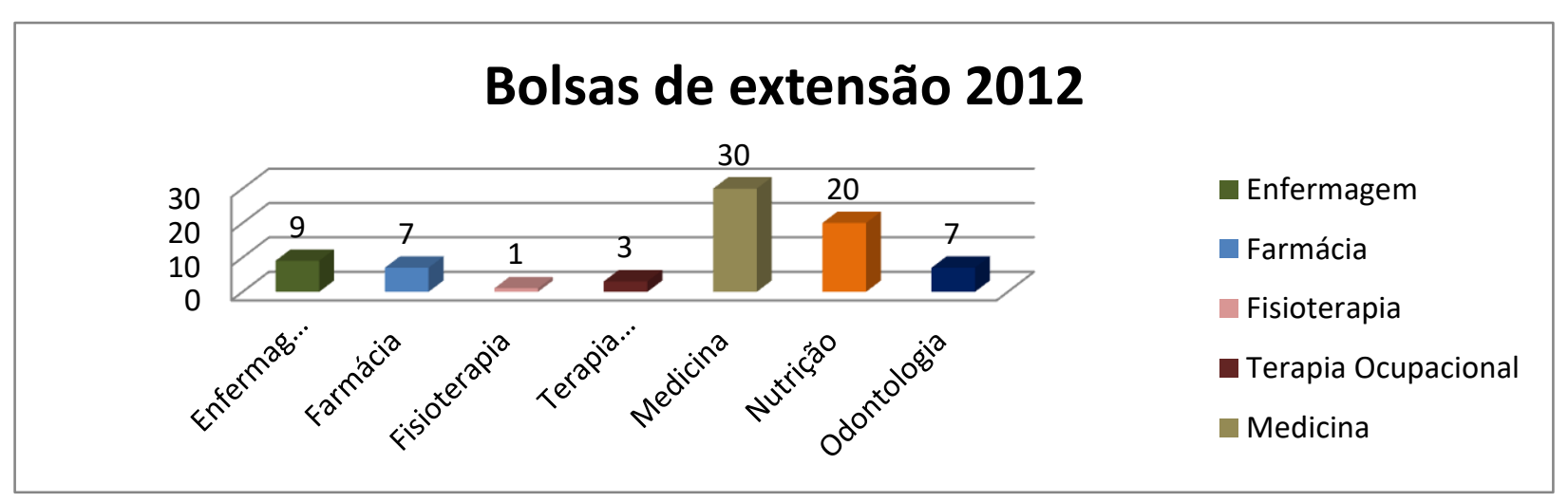

Fonte: Elaborado pelos autores (2013). 
Política Nacional de Extensão Universitária: análise da experiência do Instituto de Ciências da Saúde da UFPA

No ano de 2012, o ICS foi contemplado com 77 bolsas de extensão. De 2.573 alunos matriculados, somente 3\% é que foram contemplados como bolsistas em projetos de extensão. Estes representaram 17\% na PROEX/UFPA, que ofertou 464 bolsas de extensão para os alunos da UFPA. Considerando o quantitativo de 2.573 alunos matriculados por curso no ICS, os bolsistas representaram: 2\% de 390 alunos de enfermagem; 2\% de 297 de farmácia; 1\% de 88 de fisioterapia; 3\% de 911 de medicina; 6\% de 337 de nutrição; 1\% de 488 de odontologia; 5\% de 62 de terapia ocupacional, constatando-se, portanto, pouca oferta de bolsa de extensão destinada ao ICS.

Quadro 1 - Pesquisas desenvolvidas pelo ICS em 2012

\begin{tabular}{|c|c|c|c|c|c|c|c|}
\hline \multirow[b]{2}{*}{$\begin{array}{l}\text { Subunidade } \\
\text { acadêmica }\end{array}$} & \multicolumn{3}{|c|}{ Projetos } & \multicolumn{4}{|c|}{ Docentes } \\
\hline & $\begin{array}{l}\text { Vinculad } \\
\text { o à } \\
\text { extensão }\end{array}$ & $\begin{array}{c}\text { Não } \\
\text { vinculad } \\
\text { o à } \\
\text { extensão }\end{array}$ & Total & $\begin{array}{l}\text { Pesquisadores } \\
\text { extensionistas } \\
\text { que vincularam } \\
\text { a pesquisa com } \\
\text { a extensão }\end{array}$ & $\begin{array}{l}\text { Pesquisadores } \\
\text { extensionistas } \\
\text { que não } \\
\text { vincularam a } \\
\text { pesquisa com a } \\
\text { extensão }\end{array}$ & $\begin{array}{l}\text { Pesquisador } \\
\text { es não } \\
\text { vinculados à } \\
\text { extensão }\end{array}$ & Total \\
\hline Enfermagem & 4 & 8 & 12 & 4 & 5 & 1 & 10 \\
\hline Farmácia & 0 & 16 & 16 & 0 & 13 & 7 & 20 \\
\hline $\begin{array}{l}\text { Fisioterapia e } \\
\text { Terapia } \\
\text { Ocupacional }\end{array}$ & 0 & 7 & 7 & 0 & 2 & 4 & 6 \\
\hline Medicina & 0 & 10 & 10 & 0 & 6 & 12 & 18 \\
\hline Nutrição & 0 & 7 & 7 & 0 & 10 & 3 & 13 \\
\hline Odontologia & 2 & 30 & 32 & 4 & 8 & 23 & 35 \\
\hline Total & 6 & 78 & 84 & 8 & 44 & 50 & 102 \\
\hline
\end{tabular}

Fonte: Elaborado pelos autores (2012).

Dentre as 84 pesquisas desenvolvidas pela Unidade Acadêmica do ICS, 7\% foram vinculadas à extensão. Pode-se constatar através do Quadro 1 que: a indissociabilidade das atividades de pesquisa com a extensão no ICS demandou 7\%; as subunidades acadêmicas que coligam essa categoria de maior para menor proporção foram enfermagem 50\% e odontologia 6\%; as subunidades acadêmicas de farmácia, fisioterapia e terapia ocupacional, medicina e nutrição não vincularam esse eixo com a extensão. As atividades de pesquisa no ICS foram desenvolvidas por 28\% (102) de seu quadro de servidores da categoria docente. Dessa representação, 51\% (52) pesquisadores também estiveram vinculados em projetos de extensão. Somente 15\% (8) dos pesquisadores vincularam a pesquisa às práticas de extensão, enquanto que $85 \%$ (44) que também atuam na extensão não demandaram os objetivos da pesquisa às atividades de extensão. 
Finalmente, 49\% (50) docentes pesquisadores, exerceram somente pesquisa e de forma desintegrada da extensão.

O gráfico 2 destaca a dinâmica referente ao quantitativo de projetos de extensão desenvolvidos pelo ICS desde o ano de 1999 até 2012.

Gráfico 2 - Série histórica, em valores absolutos, desenvolvido pelo ICS

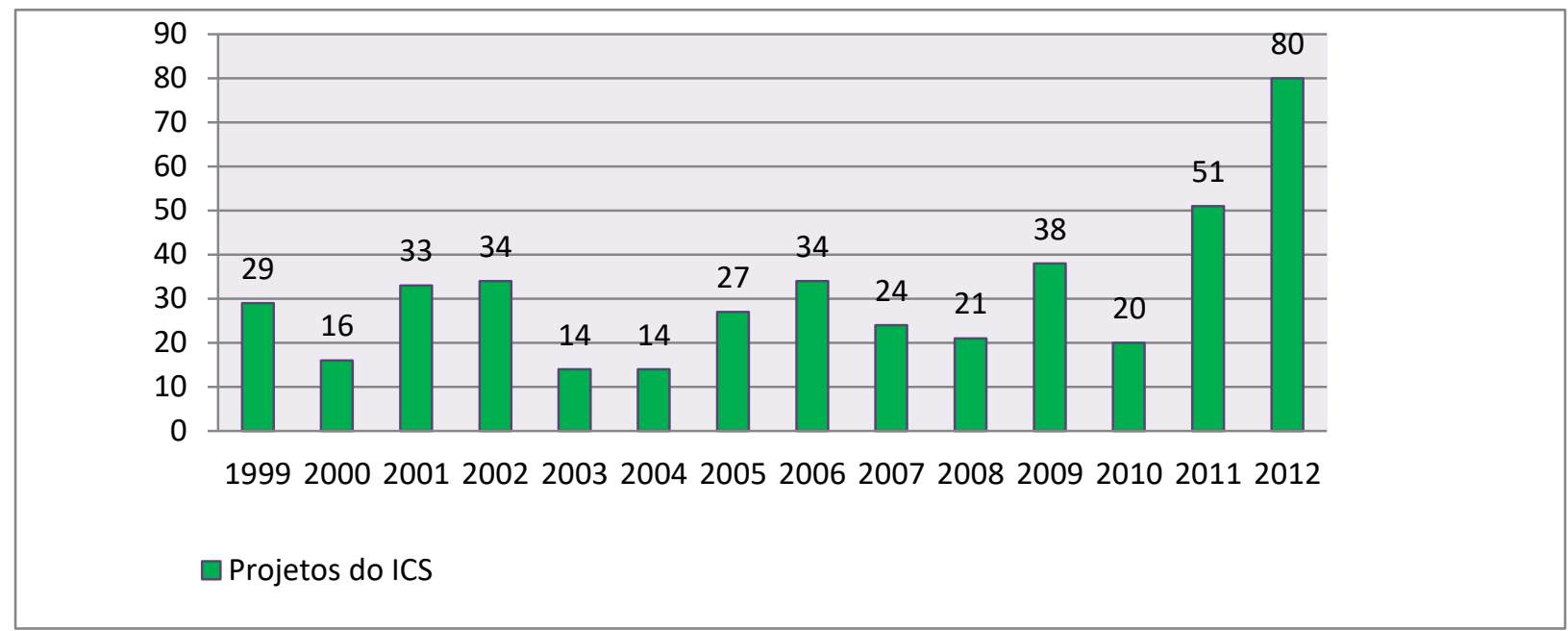

Fonte: Elaborado pelos autores (2013).

Constata-se com esse crescimento que a área da saúde vem sendo requisitada pela comunidade acadêmica, bem como devido ao aumento da demanda da comunidade adjacente à universidade. Indicativo de que falta uma política que possa cuidar da saúde da comunidade, também, fora dos limites da universidade.

O cenário acadêmico do ICS, demonstrou que os projetos de extensão foram realizados em todas as suas seis subunidades acadêmicas, totalizados em 80. Teve a participação de 28\% (103) docentes: 1\% (2) graduados, 13\% (13) especialistas, 46\% (47) mestres, 40\% (41) doutores, e 1\% (2) técnico-administrativos. Além dos docentes, contou com a participação de 2 técnicos especialistas; 77 bolsistas de cursos de graduação, distribuídos entre as subunidades acadêmicas; atendeu 83.619 usuários. Foram apresentados na PROEX 75\% (60) relatórios. Refletiram, segundo os eixos da PNEU: 98\% Interação dialógica; 18\% Interdisciplinaridade e interprofissionalidade; 23\% Indissociabilidade ensino-pesquisa-extensão; 68\% Impacto na formação do estudante; 7\% Impacto e transformação social. 


\section{RESULTADOS E DISCUSSÕES}

A pesquisa propiciou o desvelamento de alguns aspectos importantes inerentes ao objeto analisado que indicou a presença de 80 projetos de extensão para 60 relatórios entregues ao final de 2012. O primeiro aspecto importante a ser percebido se referiu á inadimplência dos relatórios por parte dos coordenadores de $25 \%$ dos projetos de extensão. Não encaminharam os relatórios ao ICS e a PROEX, que presta contas sobre as ações realizadas anualmente. Entretanto, isso não significa que não tenham realizado algo nesse sentido. Os responsáveis podem desconhecer que a apresentação do relatório está atrelada à renovação do projeto e consequente solicitação de bolsas.

O relatório de extensão, de natureza normativa, é uma ferramenta de grande importância para análise de resultados da organização. É o documento obrigatório, através do qual, se expõe o alcance ou não das atividades praticadas pelo responsável da ação. Ressalta-se que na UFPA, o Art. $5^{\circ} \int 1^{\circ}$ da Resolução n. 3.298, de 7 de março de 2005/CONSEP/UFPA determina todas as propostas e relatórios de atividades de extensão precisam ser aprovados nos Conselhos das Unidades envolvidas para posterior envio à PROEX com os documentados referentes à avaliação de mérito e atas de aprovação, para registro no cadastro de programas e projetos de extensão da UFPA/PROEX.

Uma segunda constatação é apresentada na Tabela 1, que se refere à titulação por parte dos docentes extensionistas: $10 \%$ graduados, $24 \%$ especialistas, $29 \%$ mestres e $31 \%$ doutores.

Tabela1- Representação titulação docente ICS

\begin{tabular}{l|r|r|r}
\multicolumn{1}{c|}{ Titulação } & $\begin{array}{c}\text { Total docente } \\
\text { por titulação }\end{array}$ & \multicolumn{1}{c|}{ Extensionista } & \multicolumn{2}{c}{ Não extensionista } \\
\hline Graduado & 20 & $10 \%$ & $90 \%$ \\
\hline Especialista & 53 & $24 \%$ & $76 \%$ \\
\hline Mestre & 158 & $29 \%$ & $71 \%$ \\
\hline Doutor & 130 & $31 \%$ & $69 \%$ \\
\hline Total & $\mathbf{3 6 1}$ & $\mathbf{2 8 \%}$ & $\mathbf{7 2 \%}$ \\
\hline
\end{tabular}

Fonte: Elaborado pelos autores (2013).

Embora a excelência do corpo docente do ICS ter apresentado um elevado nível de titulação demonstrado na tabela 1 , somente $28 \%$ de seus docentes participam de projetos de extensão, apesar da carga horária destinada à extensão atingir quase 30\% da carga horária mensurada para realizarem os projetos, conforme o observado na Tabela 2.

Tabela2 - Carga horária contrato institucional docente ICS 


\begin{tabular}{l|r|r|r|r}
\hline $\begin{array}{c}\text { Contrato } \\
\text { institucional }\end{array}$ & Total docente & $\begin{array}{c}\text { Carga horária ano } \\
\text { docente }\end{array}$ & $\begin{array}{l}\text { Carga horária ano } \\
\text { extensionistas }\end{array}$ & \multicolumn{1}{c}{$\begin{array}{c}\text { Carga horária } \\
\text { docente } \\
\text { destinada à } \\
\text { extensão }\end{array}$} \\
\hline $20 \mathrm{~h}$ & 29 & 27.840 & 2.880 & $10 \%$ \\
\hline $40 \mathrm{~h}$ & 159 & 305.280 & 72.960 & $24 \%$ \\
\hline $\mathrm{DE}$ & 173 & 332.160 & 119.040 & $36 \%$ \\
\hline Total & $\mathbf{3 6 1}$ & $\mathbf{6 6 5 . 2 8 0}$ & $\mathbf{1 9 4 . 8 8 0}$ & $\mathbf{2 9 \%}$ \\
\hline
\end{tabular}

Fonte: Elaborado pelos autores (2013).

A verificação da produção científica por parte do ICS foi analisada em Relatório de Atividades do ICS, do ano de 2012 e nos produtos gerados. Remetendo os produtos gerados, foram identificadas 21 publicações entre artigos e resumos em congressos local/nacional/internacional e/ou em revistas científicas. As publicações bibliográficas na esfera da extensão refletem, não apenas a dificuldade em transformar as experiências de extensão em artigos e resumos, mas, também, não há reconhecimento das revistas de cunho extensionista, pelo fato de não provocar prestígio profissional.

Concordou-se com a ideia de Vasconcelos (2006) que revistas extensionistas não são aceitas na análise da produção docente em cursos de pós-graduação, podendo ser pela dificuldade em adequar a ação extensionista a uma linha de pesquisa dentro do programa de pós-graduação, não são indexadas, ou receberam conceito "C" da Coordenação de Aperfeiçoamento de Pessoal de Nível Superior, desestimulando os docentes na elaboração de artigo pela desvalorização de seus pares. As exigências de agências de fomento e regulamentação de Mestrados e Doutorados priorizam artigos publicados em revistas internacionais indexadas em áreas específicas das Ciências da Saúde, isso porque, é o ambiente onde o índice de impacto de publicações regula o reconhecimento profissional.

Considerando que o ICS conta com infraestrutura disponível, dentre outros, nos hospitais universitários, unidades básicas de saúde, escolas públicas e privadas, organizações não governamentais, podemos alegar que o ICS subutilizou esses aspectos nos projetos e/ou nos relatórios de extensão, como, também, apresentou escassa produção bibliográfica extensionista.

O cotidiano do professor do ICS está concentrado, em sua maioria, em atividades de ensino, e a participação de $28 \%$ dos docentes se concentram na pesquisa. O Instituto poderia ter expandido o envolvimento docente em projetos de extensão nas ações de cunho social no ambiente acadêmico. Desse modo, os dados demonstram que a participação da categoria docente em projetos de extensão e apresentou no ICS como uma realidade ainda distante. 
O terceiro aspecto, exposto nas Tabelas 3 e 4, demonstra que a inclusão do pessoal técnicoadministrativo na extensão foi também limitada, e a carga horária esteve preferivelmente concentrado às ações administrativas de atividades meio em detrimento da atividade fim.

Tabela 3 - Representação técnico-administrativos ICS

\begin{tabular}{|c|r|r}
\hline Total técnico administrativo & Extensionistas & Não extensionistas \\
\hline Fonte: Elaborado pelos autores (2013). & $\mathbf{1 3 1}$ & $\mathbf{9 9 \%}$ \\
\hline
\end{tabular}

Tabela 4 - Carga horária contrato institucional técnico administrativos ICS

\begin{tabular}{|l|r|r|r|r}
\hline $\begin{array}{c}\text { Contrato } \\
\text { institucional }\end{array}$ & $\begin{array}{c}\text { Total técnico } \\
\text { administrativo }\end{array}$ & $\begin{array}{c}\text { Carga horária ano } \\
\text { técnico } \\
\text { administrativo }\end{array}$ & $\begin{array}{c}\text { Carga horária ano } \\
\text { extensionistas }\end{array}$ & $\begin{array}{c}\text { Carga horária } \\
\text { destina à extensão }\end{array}$ \\
\hline $40 \mathrm{~h}$ & 131 & 251.520 & 5.184 & $2 \%$ \\
\hline
\end{tabular}

Fonte: Elaborado pelos autores (2013).

O apoio à participação de profissionais da categoria técnico-administrativo poderia ter sido, dentre outras, na divulgação das ações desenvolvidas em projetos de extensão, no compartilhamento de experiências abrangendo discussões de problemas do cotidiano social da comunidade externa e da própria academia.

O quarto aspecto, apresentado na Tabela 5, indicou que as bolsas de extensão deliberadas ao ICS, por via de edital PROEX, absorveram 3\% do total de graduandos efetivamente matriculados nos cursos de graduação no referido Instituto.

Tabela 5 - Representação bolsista ICS

\begin{tabular}{r|r|rr}
\hline \multicolumn{1}{|c|}{ Total discente } & $\begin{array}{c}\text { Bolsistas } \\
\text { extensionistas }\end{array}$ & Não extensionistas & \\
\hline 2.573 & $3 \%$ & $93 \%$ \\
\hline
\end{tabular}

Fonte: Elaborado pelos autores (2013).

Sobre esse dado relembra-se que o estudante precisa ter a extensão em sua formação, cuja universidade se incumbiria de promover a integração entre ensino, pesquisa e extensão, pretendendo-se assim o "o perfeito equilíbrio entre a atuação de seus docentes e o anseio de seus alunos” (UNIVERSIDADE FEDERAL DO PARÁ, p. 93).

A formação discente quando distanciada das vivências sociais, sem integração do saber popular na retro alimentação do conhecimento científico, acreditamos ser um problema conceitual, filosófico e organizacional. Tal reflexão nos remete à política estabelecida em 2012 do Plano Nacional de Assistência Estudantil (PNAES, 2012) que destinou, no mesmo ano, à Universidade 
Federal do Pará o montante de R \$ 18.664.215,00 (dezoito milhões, seiscentos e sessenta e quatro mil e duzentos e quinze reais) para assistência estudantil, sem, no entanto, envolve-los em atividades de extensão. Há importância de "flexibilização para uma nova estruturação curricular, menos rígida e mais adequada às necessidades de formação de profissionais cidadãos" (PIERSON et al.,2003, p. 45).

O quinto aspecto, registrado na Tabela 6, destacou os 5 eixos da PNEU (2012) a partir dos produtos gerados nos relatórios de extensão desenvolvido pelo ICS. Encontrou-se em 98\%, a interação dialógica; 18\% interdisciplinaridade e interprofissionalidade; 23\% indissociabilidade ensino-pesquisa-extensão; 68\% impacto na formação do estudante; 7\% impacto e transformação social.

Tabela 6 - Práticas extensionistas desenvolvidas pelo ICS, segundo prerrogativas da PNEU

\begin{tabular}{l|r}
\hline Eixo da PNEU & Enquadramento \\
\hline Interação dialógica & $\mathbf{9 8 \%}$ \\
\hline $\begin{array}{l}\text { Interdisciplinaridade e } \\
\text { interprofissionalidade }\end{array}$ & $\mathbf{1 8 \%}$ \\
\hline $\begin{array}{l}\text { Indissociabilidade ensino-pesquisa- } \\
\text { extensão }\end{array}$ & $23 \%$ \\
\hline Impacto na formação do estudante & \\
\hline Impacto e transformação social & $\mathbf{6 8 \%}$ \\
\hline
\end{tabular}

Fonte: Elaborado pelos autores (2013).

Percebe-se com a análise dos dados obtidos que o item referente a interação dialógica se apresentou em 98\% dos relatórios. Referiu-se à assistência prestada para 83.619 usuários que dela se beneficiaram. Tal indicativo está assegurado pela PNEU, quando da valorização de parcerias entre a universidade e os diversos atores sociais. Assim, os projetos, na sua maioria, foram desenvolvidos em comunidades populares da Grande Belém e em escolas da rede pública.

A UFPA estabelece a importância dessa relação quando indica "[...] criar sinergia no ensino e pesquisa de graduação e pós-graduação e em suas relações com a sociedade em que propicie o conhecimento objetivo da realidade social". (PLANO DE DESENVOLVIMENTO INSTITUCIONAL, 2011-2015, p. 93). Nesse ponto, acredita-se que essa aproximação possa trazer benefícios tanto para a universidade, quanto para a sociedade.

Nesse sentido, apresentam-se agora os principais pontos identificados durante a pesquisa que visam à solução do problema proposto.

Quanto à interdisciplinaridade e interprofissionalidade demonstrou-se uma relação de (18\%). As evidências empíricas indicaram a não integração (82\%) de outras áreas e profissionais das ciências da saúde e de outras ciências inter e/ou multiprofissionais, contrariando o Art. $3^{\circ}$, Parágrafo 
Único, do regimento do próprio ICS (2010) que assegura para o desenvolvimento das atividades acadêmicas, busca a "interlocução interdisciplinar e multiprofissional”, inclusive da própria UFPA, por afirmar que a extensão se realiza "por meio de ações interdisciplinares da comunidade acadêmica objetivando a formação cidadã, a produção, e, a socialização do conhecimento" (UNIVERSIDADE FEDERAL DO PARÁ, 2009, p. 37).

A relação desse eixo indicou subunidades acadêmicas do ICS, $82 \%$ isoladas. A integração, de 18\% (11 casos) representou: 3 na enfermagem, 1 na farmácia, 1 na fisioterapia e terapia ocupacional, 2 na medicina, 1 na nutrição e 3 na odontologia, embora tenha ocorrido, quase em sua totalidade, com docentes e técnicos da área de concentração do referido Instituto.

Em relação aos conhecimentos o suporte teórico de Morin (2002) reforça que:

Para articular e organizar os conhecimentos e assim reconhecer e conhecer os problemas do mundo é necessária a reforma do pensamento. Entretanto, esta reforma é paradigmática e, não, programática: é a questão fundamental da educação, já que se refere à nossa aptidão para organizar o conhecimento. A esse problema universal confronta-se a educação do futuro, pois existe inadequação cada vez mais ampla, profunda e grave entre, de um lado, os saberes desunidos, divididos, compartimentados e, de outro, as realidades ou problemas cada vez mais multidisciplinares, transversais, multidimensionais, transnacionais, globais e planetários (MORIN, 2002, p.35-36).

O referido autor enfatiza a necessidade de se questionar o saber fragmentado, e propõe uma busca por um conhecimento mais integrado que possa trabalhar várias percepções sem menosprezar a totalidade do ser que constrói saberes.

A indissociabilidade ensino-pesquisa-extensão, representou $23 \%$ nesse tripé. Embora os relatórios de projetos de extensão tiverem gerado produção acadêmica em forma de artigos em periódicos, cartilhas, apresentações em eventos, esse enfoque foi contrariado no Quadro 9 anteriormente demonstrado, que tratou sobre as pesquisas desenvolvidas pelo ICS em 2012. A relação da pesquisa com a extensão demandou 7\%. Mesmo tendo 15\% (8) dos pesquisadores vinculado a pesquisa às práticas de extensão, 85\% desses, não propuseram os objetivos da pesquisa ao contexto social gerado nos projetos de extensão.

[...]uma universidade que se quer pautada por paradigmas democráticos e transformadores deverá, necessariamente, (re)visitar seus processos de pesquisa, ensino e extensão, valorizando, também, os saberes do senso comum, confrontados criticamente com o próprio saber científico, comprometendo a comunidade acadêmica com as demandas sociais e com o impacto de suas ações transformadoras em relação a tais demandas. (FORPROEX, 2006, p. 41). 
Refletir a indissociabilidade ensino, pesquisa e extensão, com base na missão da universidade, deve a pesquisa, perpassar o ensino e a extensão por meio de ações planejadas e dirigidas pelos gestores universitários, assim como, requer comprometimento por parte dos docentes/pesquisadores nas ações formativas que desenvolvem no campo científico em que atuam.

E sobre o item impacto na formação do estudante apresentou o resultado de $68 \%$. Refletiu que o conhecimento pelo contato direto, com as grandes questões contemporâneas, cria espaços para reafirmação e materialização dos saberes, de compromissos éticos e solidários.

A formação do aluno está em induzi-lo à (re)criar e responder aos desafios, capaz de gerar tecnologias e de manter a habilidade de aprender e recriar permanentemente, "transformá-lo no locus de construção/produção do conhecimento, em que o aluno atue como sujeito da aprendizagem" (Plano Nacional de Extensão, 2001). Como defende o Fórum de Pró-Reitores das Universidades Públicas Brasileiras, é imprescindível a interação do discente com a sociedade para situá-lo historicamente, identificá-lo culturalmente e referenciar a sua formação técnica à realidade.

Por fim, o item sobre impacto e transformação social contabilizou 7\%. O ICS quando estabeleceu a inter-relação com os setores sociais, numa relação transformadora, fez assistência, característica mais presente dentre todos os eixos da PNEU (98\%) no referido instituto. Não se trata apenas inovar nos cenários, mas situar o contexto em perspectiva de transformação social.

Refletir tal pressuposto não significa pensar, tão somente, na direção do desenvolvimento econômico das nações, pressupõe, também, destinar estudos às transformações sociais como um campo de investigação para formulação de ações concretas em perspectiva social e política aberta, às humanidades. Compreende desenvolvimento humano através de melhorias das condições de saúde, educação, trabalho, segurança, dentre outros. Possibilitar à sociedade caminhos para participação na vida pública é "[...]processo que permite alargar as oportunidades de escolha dos indivíduos [...]que são criadas pela expansão das capacidades e possibilidades humanas”. (STREETEN, 1999, p. 16). Por conseguinte, auxilia a sociedade buscar subsistência, assim como, conduzir-se na vida frente às consequências das transformações mundial. 


\section{CONCLUSÃO}

Através do subsídio de 80 projetos e 60 relatórios de extensão do ano de 2012 do ICS da UFPA, que se destacou das demais Unidades acadêmicas da UFPA, pelo quantitativo de projetos de extensão durante os anos de 1999 à 2012. Para responder a questão se os produtos gerados, por via de projetos, nas práticas extensionistas desenvolvidas pelo ICS/UFPA, cumprem as prerrogativas da Política Nacional de Extensão Universitária, apoiou-se na pesquisa em materiais bibliográficos e em documentos oficiais que permitiram a análise de dados quantitativos e qualitativos que comportou verificar os indicadores dos produtos gerados, como também testarem a hipótese de que os projetos de extensão do ICS ainda não estão impactando na formação discente face ao conhecimento transformador, o que é reforçado por uma extensão que institucionaliza o modelo assistencialista em detrimento de uma concepção reflexiva que conduza à consciência em perspectiva de transformação social.

A hipótese traçada nesse estudo pode ser refutada parcialmente, haja vista que se consagrou nos relatórios dos projetos de extensão do ICS que as ações estão impactando na formação discente face ao conhecimento transformador, embora a participação discente não esteja numericamente contemplada nos relatórios de extensão analisados, constando somente os bolsistas. Decorrente das estatísticas demonstrarem pouca integração nos eixos interdisciplinaridade e interprofissionalidade, indissociabilidade ensino-pesquisa-extensão, e, impacto e transformação social atribuíram-se que o eixo pertinente ao impacto na formação do aluno poderá ainda não está impactando para transformação social.

Também se refuta parcialmente a afirmativa que trata que a extensão do ICS se institucionaliza de diferenciados modelos, evidenciando-se como assistencialista em detrimento de uma concepção reflexiva que conduza a uma consciência em perspectiva de transformação social. Tal questão foi negada no eixo interação dialógica, decorrente do ICS fazer assistência e não assistencialismo, haja vista que houve garantia aos usuários que se beneficiam da extensão, o direito à assistência, o qual se efetivou, durante o ano de 2012, de forma sistemática. Dessa forma, pode-se adjudicar que o modelo de extensão do ICS é assistencial desenvolvido através de prestação de serviços, contudo, não pode assegurar a contribuição para transformação social.

Extensio: R. Eletr. de Extensão, ISSN 1807-0221 Florianópolis, v. 14, n. 26, p. 23-44, 2017. 
Embora o ICS seja a Unidade Acadêmica mais produtiva, em números de projetos de extensão na UFPA, tendendo a uma ampliação nos próximos anos, as evidências empíricas demonstram, de modo geral, que as práticas da extensão desenvolvidas não atenderam as orientações da política nacional de extensão universitária.

Por fim, os resultados revelaram que as prerrogativas da PNEU ficaram muito aquém de serem atingidas pelos produtos do ICS, quando se tratou de interdisciplinaridade e interprofissionalidade, indissociabilidade ensino-pesquisa-extensão, e, impacto e transformação social. Além disso, foi encontrada pouca participação por parte dos docentes, discentes e técnicoadministrativos do ICS em dita atividade.

\section{REFERÊNCIAS}

ANTUNES, Celso. Como transformar informação em conhecimento. 2. ed. Petrópolis. Rio de Janeiro: Vozes, 2002.

BOGDAN, Roberto C.; BIKLEN, SáriKnopp. Investigação qualitativa em educação. Trad. Maria João Alvarez, Sara Bahia dos Santos e Telmo Mourinho Baptista. Porto: Porto, 1994.

BRASIL. Lei de diretrizes e bases da educação, Art. 77, $\mathbb{S} \mathbf{2}^{\mathbf{0}} .2013$. Link: http://wikipedia.org/wiki/Lei_de_Diretrizes_e_Bases_da_Educação_Nacional.

Ministério da Educação e Cultura. Lei no 4.042, de 20 de dezembro 1961. Estabelece as Diretrizes e Bases da Educação Nacional. Brasília, DF, 1961.

BRUNER, J. J. Estado y educación superior en América Latina. In: NEAVE, G; VAN VUGHT, F.A. (Ed.) Prometeo encadenado: estado y educación superior en Europa. Barcelona: Gedisa, 1994. (Colección Debate Socioeducativo).

CERVO, Amado. BERVIAN, Pedro A. DA SILVA, Roberto. Metodologia científica. 7. ed. São Paulo: Prentice Hall, 2011.

CHAUÍ, Marilena. Convite à filosofia. São Paulo: Ática, 2007.

FONTES, E. J. O. UFPA 50 ANOS: histórias e memórias. Belém: EDUFPA, 2007.

FÓRUM de Pró-Reitores de Extensão das Universidades Públicas Brasileiras e SESU / MEC. Plano Nacional de Extensão. Brasil 2000-2001. Link: http://www20.fcm.unicamp.br/extensao/.pdf. . POLÍTICA NACIONAL DE EXTENSÃO UNIVERSITÁRIA - PNEU. Manaus, 2012.

GURGEL, R. M. Extensão universitária: comunicação ou domesticação. São Paulo: Cortez, 1986. 
HUMBOLDT, W. Sobre a organização interna e externa das instituições científicas superiores em Berlim. In: CASPER, G; HUMBOLDT, W. Um mundo sem universidades? Rio de Janeiro: EdUERJ, 1997.

KANT, Immanuel. Crítica da razão pura. São Paulo: Martin Claret, 2001.

MORIN, E. Os sete saberes necessários à educação do futuro. 6. ed. São Paulo: Cortez; Brasília, DF: UNESCO, 2002.

NOGUEIRA, M. D. P. Extensão universitária: diretrizes conceituais e políticas: documentos básicos do Fórum Nacional de Pró-Reitores de Extensão das Universidades Públicas Brasileiras. Belo Horizonte: PROEX; UFMG, 2000.

OLIVEIRA, Valéria Rodrigues de. Desmitificando a pesquisa científica. Belém: EDUFPA, 2008.

PIERSON, Alice Helena Campos; CORTEGOSO, Ana Lucia; ARAÚJO FILHO, Targino de. Flexibilização curricular: experiências e perspectivas. In: THIOLLENT, Michel; CASTELO BRANCO, Alba Lúcia; GUIMARÃES, Regina Guedes Moreira; ARAÚJO FILHO, Targino de. (Org.). Extensão universitária: conceitos, métodos e práticas. Rio de Janeiro, v. 1, p. 41- 55, 2003.

PLANO NACIONAL DE ASSISTÊNCIA ESTUDANTIL - PNAES. 2012. Link: http:// portal.mec.gov.br/component/tags/tag/32725.

SEVERINO, Antônio Joaquim. Metodologia do trabalho científico. 21. ed. São Paulo: Cortez, 2000.

STREETEN, Paul. United Nations development programme: ten years of human development. New York: Oxford University Press,1999. Link: <http://hdr.undp.org/en/media/HDR_1999_EN.pdf.

TEIXEIRA, Elizabeth. As três metodologias: acadêmica, da ciência e da pesquisa. 10. ed. Petrópolis, RJ: Vozes, 2010.

TOLBERT, Pamela S; ZUCKER, Lynne G. A institucionalização da teoria institucional. In: CLEGG, S. R; HARDY, C; NORD, W. R. Handbook de estudos organizacionais: modelos de análise e novas questões em estudos organizacionais. São Paulo: Atlas, 1999. p. 27-57. v.1.

UNIVERSIDADE FEDERAL DO PARÁ. Estatuto\& regimento geral. Belém, 2009. p. 19, 20, 24, 25. Link: http://www.ufpa.br/sege/boletim_interno/downloads/estatuto/estatuto.pdf.

Estatuto \& regimento geral. Belém, 2009. p. 18, 19. art. 20, 3o. Link: http://www.ufpa.br/sege/boletim_interno/downloads/estatuto/estatuto.pdf.

Estatuto \& regimento geral. Belém, 2009. p. 35-36, 37art. 56, 64, 66, 67. Link: http://www.ufpa.br/sege/boletim_interno/downloads/estatuto/estatuto.pdf. 
Política Nacional de Extensão Universitária: análise da experiência do Instituto de Ciências da Saúde da UFPA

. CONSELHO SUPERIOR DE ENSINO, PESQUISA E EXTENSÃO - CONSEP.

Resolução $\quad$ n. $3.298 . \quad 2001 . \quad$ Inciso primeiro. Link: https://www.portal.ufpa.br/docsege/3298atividadesdeextensaoufpa.pdf.

Resolução no. 3.633. Belém, 18, fevereiro de 2008. art. Art. $4^{\circ}$, Art. 5, 59, 60). Link: http://www.ufpa.br/cppd/Regulamentograduacao363308.pdf.

- CONSELHO UNIVERSITÁRIO-CONSUN. Instituto de Ciências da Saúde- ICS; FACULDADE DE FISIOTERAPIA E TERAPIA OCUPACIONAL. Regimento. Resolução n. $688.2010 . \quad$ Art. 41.Link: http://www.ufpa.br/sege/boletim_interno/downloads/resolucoes/consun/2010/688\%20Cria $\% 20$ Fisioterapia $\% 20 \mathrm{e} \% 20$ altera $\% 20 \mathrm{RI} \% 20 \mathrm{ICS}$.pdf.

INSTITUTO DE CIÊNCIA DA SAÚDE- ICS. Relatório anual de atividades, Belém, 2012, p. 1, 15, 55, 57.

PLANO DE DESENVOLVIMENTO INSTITUCIONAL - PDI. 2011/2015, Belém, 2011. p. 18, 20,27-28,30, 49, 93, 94. Link: http://www.proplan.ufpa.br/doc/ Apresentacao_PDI.pdf.

.PRÓ-REITORIA DE PLANEJAMENTO E DESENVOLVIMENTO INSTITUCIONAL - PROPLAN. Plano de Gestão Orçamentária, Belém, 2012, p. 16, 27. Link: http:// www.proplan.ufpa.br/doc/PGO_2012_Versao_Aprov.pdf. 